\title{
Julia Adams, Elisabeth Clemens y Ann Shola Orloff (Eds.). Remaking modernity, Duke University Press, 2005, 612 pp., Durham y Londres
}

\author{
Naim Bro Khomasi ${ }^{1}$
}

Remaking Modernity es una compilación de trabajos escritos por varios de los principales exponentes de la sociología histórica norteamericana. La tesis central del libro señala que esta subdisciplina ha experimentado un cambio tal que permite hablar hoy -desde los años 1990 en adelante- de una "tercera ola", en contraste con una "segunda ola" dominante en las dos décadas previas, y con una "primera ola" que vendría a ser el voluminoso trabajo sociológico-histórico de los clásicos. Los contribuyentes del volumen serían muestra viva de esta transformación. Todos ellos se mueven dentro de esta tesis general, poniendo de relieve cómo distintas áreas de las ciencias sociales pueden ser enriquecidas atendiendo a los nuevos desarrollos conceptuales de esta tercera ola. En términos sustantivos, los autores proponen que las categorías centrales de la sociología histórica se han basado en supuestos "modernistas" que hoy requieren revisión, no para dar por superada la modernidad y todo su bagaje conceptual, sino que para reconstruir sus supuestos de base-de ahí el título del libro-.

La segunda ola es para los autores una corriente intelectual que propulsó el renacimiento de la perspectiva histórica en las décadas de los 70 y los 80, en oposición al modo ahistórico predominante de hacer sociología de aquel período, específicamente al estructural-funcionalismo y al empirismo ateórico. Fue también una corriente políticamente comprometida que cobró fuerza en el contexto de los movimientos sociales y de la amplia audiencia marxista de su tiempo. Aquí pueden ser incluidos autores de la talla de Barrington Moore, Craig Calhoun, Charles Tilly, Theda Skocpol, Michael Mann y Maurice Zeitlin, entre otros. Si bien no todos marxistas, estos autores formularon preguntas estrechamente vinculadas con la problemática de esa corriente teórica, en términos de su interés por la economía política y de la adopción de temáticas como la transición al capitalismo, las revoluciones, la industrialización, la construcción de estados y la formación de clases sociales. Las soluciones teóricas que encontraron, sin embargo, tendieron a extenderse más allá del marxismo, especialmente por la importancia que asignaron al Estado y por su reivindicación de la autonomía relativa de la política. Es por ello que los autores caracterizan la segunda ola como una particular alianza entre Marx y Weber: el primero ofrecía terreno común para el diálogo, especialmente en el supuesto de que los intereses materiales determinan las formas de acción política, subjetividad, y cultura, mientras que el segundo permitía explicar la diversidad de casos anómalos que el marxismo no explicaba.

La tercera ola, a diferencia de la segunda, no tiende a la convergencia en torno a un marco teórico único. En efecto, los autores identifican dentro de la sociología histórica actual comunidades intelectuales tan diferentes entre sí como el institucionalismo, el rational choice, el giro cultural, el feminismo y los teóricos de la colonialidad y de la formación racial

\footnotetext{
1 Sociólogo, Universidad de Chile. Correo electrónico: E-mail: naim.bro@gmail.com
} 
de los imperios. Pese a su heterogeneidad, estas variadas formas de producción intelectual tienen en común la crítica de las categorías modernistas de la segunda ola, en particular de la combinación fuerte entre determinismo estructural, con foco en la economía política, y un modelo utilitarista de la acción social.

Un primer punto de inflexión tiene que ver con el problema de la agencia y la estructura. Para los teóricos de la segunda ola era permisible deducir los intereses de los actores directamente de la posición de estos en la estructura de clases, y definir su acción únicamente a partir de la prosecución de los fines que imponían dichos intereses. Para la nueva generación de sociólogos, en cambio, esta perspectiva es relativizada por la importancia creciente que se asigna en el proceso de estructuración a una agencia culturalmente constituida, y por el reconocimiento de los modos complejos y contingentes por los cuales los actores comprenden sus propias posiciones en la sociedad. El sujeto racional moderno deja de tener carácter ontológico universal y pasa a ser visto como un individuo históricamente construido, al cual además se le relevan otras lógicas de acción que no se reducen a la instrumental. Y se reconocen los condicionamientos de las estructuras, pero se señala que los individuos participan de múltiples estructuras y no sólo en las de la economía política, y por tanto tienen el potencial de definir sus acciones en referencia a múltiples principios, cuyas formas específicas de combinación es un trabajo contingente, y cuya estabilización en cierto período histórico es un logro social que en sí mismo amerita explicación.

Como consecuencia de esta relativización del peso de las estructuras y de la univocidad de la acción, los sociólogos de la tercera ola amplían el abanico de actores relevantes en el estudio de lo social. Ya no solo las clases sociales, sino también las mujeres, los grupos religiosos, los grupos etarios y los grupos étnicos pasan a ocupar el centro del escenario. Y mientras antes la economía política abarcaba gran parte del abanico temático de la sociología histórica, desde los años 1990 en adelante se reivindica también el rol de la cultura, se relevan formas capilares de poder, y se vuelve a investigar fenómenos como la religión, la emoción y las motivaciones no racionales de la guerra y de la violencia de los Estados, todo ello en contextos geográficos no limitados a Estados Unidos y Europa. Los tópicos clásicos de la segunda ola ciertamente no son abandonados, de hecho muchos de los capítulos del libro los abordan de lleno, pero se cuestionan de las premisas de base sobre las que se habían estudiado.

Otro punto de inflexión que diferencia la segunda y la tercera ola tiene que ver con los imaginarios del desarrollo histórico. La segunda ola estuvo fuertemente influenciada por un imaginario característico del siglo XIX que entendía la historia como una secuencia de tipos societales internamente coherentes, intermediados por crisis o transiciones que marcaban rupturas fuertes entre cada etapa, y cuyo sentido general era definido por un thelos -la razón, la libertad, la igualdad-. Desde esta visión de la historia, la modernidad tenía clara preeminencia frente a otras etapas. La tercera ola, en cambio, entiende el desarrollo histórico como una cadena de probabilidades mediadas por la capacidad humana de agencia. En este sentido, se reconoce la ascendencia de la contingencia en la historia, 
es decir, la idea que señala que los eventos y procesos efectivos son la realización de una de las múltiples posibilidades de cambio o de reproducción social. Así, desde un punto específico del tiempo y en el contexto de condiciones estructurales dadas, no todas las trayectorias de cara al futuro son igualmente factibles, pero hay más de una posible. Ello tiene sentido en la medida en que se asigna a la agencia y a la cultura un rol importante en el devenir histórico y que se reconoce que los actores operan en múltiples esferas sociales causalmente irreductibles entre sí, según lo cual no es posible visualizar un principio único -e.g. el modo de producción- que en todo tiempo y espacio haga primar su lógica frente a otras esferas en una dirección causal única.

El texto se divide en cinco partes, más una introducción extensa y sustantiva escrita por las tres editoras (Adams, Clemens y Orloff), y un epílogo de la misma calidad elaborado por Elisabeth Clemens. Los desarrollos más generales del libro (revisados arriba) corresponden a estos dos apartados. El resto de las cinco partes corresponden a conjuntos de tres capítulos cada uno que tratan sobre los grandes temas de la sociología histórica.

En la primera parte, "Sociología histórica y fundamentos epistemológicos", el capítulo de Richard Biernacki es una reflexión en torno a los modelos de la acción social y a las posibilidades conceptuales de una teoría que historice la constitución de distintos tipos de racionalidad. Zine Magubane realiza una reconstrucción histórica sobre la forma como la sociología ha entendido la historia de pueblos no europeos y las relaciones de colonialismo e imperialismo. El capítulo de George Steinmetz desarrolla un análisis de los supuestos epistemológicos sobre los cuales se construyó la sociología desde mediados del siglo XX en Estados Unidos en adelante, prestando especial atención a la relación problemática que ha tenido la sociología histórica con la epistemología.

En la parte segunda, "Formación del Estado y la sociología histórica", Philip Gorski elabora una reflexión en torno a la necesidad de entender la emergencia de diversos rasgos importantes de la modernidad, particularmente del proceso de formación del Estado nacional, a la luz de las transformaciones religiosas de la modernidad temprana. Ann Shola Orloff revisa los nuevos desarrollos teóricos acerca de la historia de los Estados de bienestar. Y Edgar Kiser y Justin Baer desarrollan un modelo que utiliza argumentos del rational choice para explicar la emergencia ubicua del Estado burocrático en las sociedades modernas.

La tercera parte, "Historia y Contención política", agrupa tres capítulos sobre guerra, acción colectiva y revoluciones. Meyer Kestbaum describe el desarrollo reciente de una sociología de la guerra que estuvo ausente por mucho tiempo de la reflexión sociológica, y muestra cómo los distintos tipos de guerra han tenido distintos efectos en las sociedades. Roger Gould plantea el carácter particularmente problemático del estudio de la acción colectiva para la sociología histórica, y, criticando ciertas tendencias historicistas, muestra cómo es posible encontrar patrones comunes en múltiples episodios de acción colectiva. Y Nader Sohrabi plantea la necesidad de entender episodios revolucionarios desde el punto de vista de la inserción de los países en entramados globales de comunicación y de transmisión de repertorios de contención, mostrando cómo este prisma analítico arroja un nuevo entendimiento de las revoluciones en Irán y Turquía a inicios del siglo XX. 
La cuarta parte se denomina "Capitalismo, Modernidad, y la esfera económica". Aquí, Bruce Carruthers muestra la convergencia actual entre sociología económica y sociología histórica y apunta los beneficios que resultan de la misma. Rebecca Jean Emigh hace una revisión de los supuestos que están a la base de las teorías clásicas sobre la transición al capitalismo y describe los planteamientos actuales críticos de tales teorías. Y Ming-Cheng Lo reconstruye el pensamiento sobre las profesiones desde un punto de vista histórico y muestra cómo este ámbito de investigación constituye un lente privilegiado para entender dinámicas centrales de la modernidad.

En la última parte, "Política, Historia, e Identidades colectivas", Lyn Spillman y Russell Faeges sistematizan los desarrollos actuales acerca del fenómeno de la nación, otro tema que ha estado ausente en la discusión sociológica, hecho sorpresivo dada su centralidad en la modernidad. Margaret Somers hace lo propio en relación con el tratamiento que ha hecho la sociología del tema de la ciudadanía. Y Bruce Brubaker explora en las nociones de etnia y raza, criticando los supuestos aproblemáticos del concepto de "grupo" que les subyacen. Al final del volumen, el epílogo de Elisabeth Clemens realiza un paneo general sobre los desarrollos teóricos que definen una nueva manera de entender la relación entre historia y sociología.

En suma, Remaking Modernity es un excelente texto para quien quiera conocer el estado del arte de la sociología histórica, no solo porque en él contribuyen muchos de sus principales exponentes actuales, sino también porque estos hacen un importante esfuerzo reflexivo en torno al legado, al presente y a las posibilidades de desarrollo futuro de la subdisciplina. El aporte que realiza cada autor es doble: por un lado, un aporte sustantivo, donde desarrolla un tema concreto de acuerdo con su trayectoria académica particular, y, por otro, un aporte reflexivo, donde vincula los resultados de su trabajo con las transformaciones conceptuales más generales que ha experimentado la sociología en las últimas décadas. En este sentido, el texto no es la simple agregación de buenos capítulos bajo el rótulo de "sociología histórica", sino que eminentemente un esfuerzo colectivo coherente que converge en una reflexión acerca del estado actual de la subdisciplina.

Lo único que se echa de menos en el libro, que por lo demás es de mucha calidad, es la inclusión de autores de otras latitudes más allá de Estados Unidos. En un tiempo en que la sociología se autocomprende en términos globales, y que experimenta una tendencia a incluir en su seno visiones de mundo y desarrollos intelectuales de orígenes cada vez más diversos, tal inclusión se hubiera agradecido. Los editores, en todo caso, explicitan y se hacen cargo de este punto, aludiendo a la especificidad que ha tenido la historia del pensamiento sociológico en Estados Unidos, la cual es justamente el objeto del volumen.

En el lector latinoamericano, Remaking Modernity suscita la pregunta por nuestra propia sociología histórica. Aquello que en Estados Unidos fue la segunda ola, en América Latina tuvo una contraparte muy potente en los teóricos de la dependencia. El debate intelectual de aquel período tuvo un evidente acento histórico-teórico que giró en torno a preguntas sobre si América Latina fue capitalista desde el comienzo o no, sobre las etapas del desarrollo de la región, sobre la capacidad de actores sociales concretos de cambiar el curso de la historia, 
y sobre las posibilidades históricas de transitar al socialismo. En la actualidad, la perspectiva histórica se utiliza en los estudios sobre colonialidad y modernidad latinoamericana, y en otras áreas de conocimiento, sin embargo, en el grueso de la disciplina esta perspectiva no posee el mismo dinamismo que en otras regiones del mundo. Cabe el desafío, entonces, de impulsar aún más la reflexión sociológica en el terreno de la amplia y rica historia latinoamericana, para de este modo tener mejores herramientas para comprender el presente y el futuro de la región. 